\title{
Por uma política de valorização das Revistas acadêmicas na área de História
}

Resumo: A ideia deste editorial coletivo surgiu, foi discutida e elaborada no Fórum de Editores de periódicos da ANPUH-Brasil, entre os meses de setembro e novembro de 2021. Buscou-se na iniciativa elementos consensuais no campo da História, aqui representado pelos editores de vários dos periódicos da área, em defesa dos artigos publicados, dos trabalhos realizados pelas revistas e por suas equipes editoriais. Destacar o valor dos nossos periódicos e artigos não é menosprezar ou reduzir o papel do livro autoral junto à área, mas é reconhecer que a manutenção e existência dos periódicos, enquanto trabalho de médio e longo prazo, requerem atenção e trabalhos específicos, nem sempre reconhecidos pelas instâncias e instituições que os abrigam. De tal modo, esta iniciativa visa a lançar luz e fomentar o debate sobre o papel dos periódicos e seu lugar na circulação de conhecimento, o papel das equipes editoriais (editores, pareceristas, entre outros), necessidade de financiamento público (na garantia do acesso aberto diamante) e importância dos apoios institucionais.

$\mathbf{N}$ as últimas três décadas, o lugar e o papel dos artigos científicos publicados nos periódicos ampliaram-se significativamente no campo das Humanidades, seja como parte de mudanças no universo de potenciais autores e leitores devido à expansão de cursos de graduação e pós-graduação, seja este processo resultado, em parte, da indução da avaliação feita pela CAPES, a agência de consolidação da pós-graduação nacional. No entanto, apesar do crescente volume de artigos e de revistas publicados (incluindo periódicos discentes), não observamos um crescimento equivalente nos usos destas referências, tanto em outros artigos, teses e dissertações e livros quanto sua presença em ementas de cursos de graduação e pós-graduação. Caberia perguntar: será que lemos e acompanhamos os artigos que saem nos periódicos, ao menos, nas áreas de nossas especialidades?

A resposta parece ser não, o que pode indicar uma certa distorção: apesar de ser um elemento altamente valorizado na avaliação dos programas de pós-graduação, e envolver um grande trabalho de avaliação e edição por parte das equipes editoriais de periódicos, bem 
como de produção e aperfeiçoamento de cada artigo avaliado, sua inserção no cotidiano de docentes e pesquisadores em História não parece ser central. Se tomarmos como certo que os artigos deveriam representar os primeiros resultados de pesquisas originais, não caberia a nós, como comunidade, valorizá-los? Nos arriscamos a dizer que duas ações deveriam ser pensadas de modo a contribuir com uma desejável mudança nesse quadro: primeiramente, uma ampliação nos usos de artigos científicos na prática de pesquisa, de formação, de ensino e de preparo e seleção de novos pesquisadores; além disso, o reconhecimento pleno dos trabalhos realizados pelas equipes editoriais (editores de periódicos e avaliadores/pareceristas, em especial), em sua dimensão técnica e, sobretudo, acadêmica.

É um consenso partilhado entre nós a importância dos livros autorais como fruto da consolidação de pesquisas originais, muitas delas acumuladas ao longo de anos. Os artigos de periódicos, no entanto, podem ter outra função: a de apresentar novidades de pesquisas, de abordagens, de revisões do campo historiográfico, de reflexões sobre a docência e sua prática etc., cujo caráter exploratório é sempre bem-vindo. Seria salutar que alguma reflexão sobre seus formatos estivesse presente nos nossos espaços formativos. Mas provavelmente a questão passe por um gargalo: como nós, enquanto campo, desejamos potencializar a leitura e o uso dos artigos publicados se durante a formação do historiador (no nível de graduação e pós-graduação) a imensa maioria dos itens bibliográficos das ementas disciplinares são de livros? E mesmo os textos obrigatórios valorizam capítulos muito mais que artigos? Sem uma formação que prepare a comunidade historiadora para consultar, usar e refletir sobre este tipo de referência, considerando inclusive a crescente multiplicação de ferramentas digitais que subsidiam indexadores e bases de periódicos plurais, dificilmente esse quadro se alterará.

Observando o que as revistas do campo têm feito ultimamente, cabe apontar que utilizamos muito pouco o que oferecem para reflexão e atividades de formação. Além dos tradicionais dossiês, as seções de debate, informes de pesquisas, entrevistas, blogs, entre outros, e mais recentemente lives e discussões on-line que aumentaram progressivamente com a pandemia iniciada em 2020, quase nada disso parece ser material orgânico de discussão sobre seus temas e produções. Poucos são os cursos que promovem reflexão e acompanhamento de revistas nas áreas especializadas, dentro e fora do Brasil, o que pode ser especialmente significativo na pós-graduação, onde a necessidade de atualização das novas pesquisas diante da produção referente a cada tema é imperiosa, devido ao fato dos periódicos serem veículos de comunicação das pesquisas mais recentes, bem como espaços de interações recorrentes. E o que dizer de cursos que promovam atividades formativas acerca da produção editorial em seus vários níveis, até mesmo de avaliadores, o que conta com ainda experiências inovadoras muito pontuais.

Ao mesmo tempo que esse conjunto de indícios sugere um baixo investimento na qualificação do debate acadêmico, stricto sensu, convoca a comunidade de historiadores a reavaliar e aperfeiçoar suas práticas. Nada disso fará sentido se não investirmos na valorização 
do trabalho editorial como um todo: a atuação dos editores, conselhos, assistentes e avaliadores. Este processo envolve ao menos dois âmbitos, fundamentais para o fortalecimento do debate qualificado no campo da história: (a) reconhecimento institucional do trabalho acadêmico e técnico daqueles envolvidos no processo de edição de um periódico; e (b) reconhecimento do trabalho acadêmico na elaboração dos pareceres dos artigos avaliados.

A atuação das equipes, em seus mais variados níveis, requer um reconhecimento institucional que talvez deva ter um forte arrimo dentro de nossos próprios departamentos, programas, universidades, sem contar nossa avaliação como pesquisadores e docentes. A condução e execução dos trabalhos dos periódicos requer horas a fio de trabalho voluntário em prol do campo científico e, na imensa maioria das vezes, sequer é levado em conta como atividade profissional pelas instituições - salvo raríssimas exceções. O mesmo se pode dizer dos trabalhos dos discentes envolvidos nos processos de editoração de periódicos que deveriam ter computadas, ao menos, as horas que essas atividades tomam, se as entendemos realmente como experiência central na sua formação. Os editores arcam com o tempo, o acúmulo de trabalho (vale dizer que quanto menor o periódico, mais o trabalho é centralizado em poucas pessoas), a dificuldade de encontrar pareceristas especialistas dispostos e disponíveis para análise de nossos artigos, o restrito apoio técnico institucional que os obriga à busca pelo aprendizado sobre novas ferramentas de gestão editorial, de controle de originalidade, de indexação e de difusão de nossa produção, incessantemente, tudo para garantir a publicação de nossos artigos mantendo o rigor da periodicidade mais adequada possível.

Infelizmente não é muito diferente no trabalho dos pareceristas. Na imensa maioria, temos uma atuação praticamente voluntária e anônima, em que a demanda pela sua grande especialização e qualidade do parecer tem um mínimo de reconhecimento (uma declaração de atividade realizada, a ser computado em relatórios de atividades de departamentos e/ou no programa), que é bem aquém da contrapartida ofertada. Não à toa, não há revista que não enfrente atualmente dificuldade em encontrar pareceristas, e ainda mais dispostos e com tempo para dedicação às avaliações. Enquanto não valorizarmos o trabalho dos pareceristas como produção intelectual sumamente qualificada, novamente estaremos com poucas possibilidades de reverter o quadro. Ainda mais diante dos novos desafios que se colocam às revistas hoje em dia para que sejam veículos muito mais dinâmicos e ativos na interação com a comunidade, e menos simples repositórios de textos.

Arriscamos dizer que o reconhecimento de todas essas etapas de produção e avaliação pode apontar para um saudável caminho contrário ao produtivismo, em prol de uma cultura de maior leitura e interação com os periódicos. Alterar a cultura consolidada da área no que toca às revistas e incentivar uma maior experimentação diante das possibilidades atuais das plataformas digitais é algo mais que bem-vindo atualmente, mas que demanda tempo precioso de trabalho de todas e todos nós. 
Se nada disso é possível sem recursos humanos e técnicos qualificados, é inviável sem recursos financeiros. Editar um periódico de qualidade exige recursos financeiros no pagamento de equipes especializadas - revisão, tradução, diagramação, apoio de secretários/ assistentes editoriais, marcação XML, hospedagem de sistema de gerenciamento do fluxo editorial, registro DOI, acompanhamento dos processos de indexação, entre outros. A mudança do suporte de papel para o digital pode ter apresentado uma ideia ilusória de que os custos se reduziram. No entanto, de modo geral, os custos ficam equivalentes ou maiores, na medida em que trabalhos mais especializados se tornaram imperativos, assim como a necessidade de criação/disponibilização de sistemas que garantam não apenas o acesso digital no curto e médio prazo, mas também sistemas digitais que assegurem a guarda e o acesso a nossas produções no longo prazo. Afinal, são esses acervos que testemunham parte substantiva de nosso debate historiográfico e, portanto, de sua memória. Nesse sentido, financiar a publicação de um livro é muito mais fácil do que o complexo processo editorial que sustenta cada artigo publicado em uma revista acadêmica, cujo exigente trabalho, constante e qualificado, não pode ser como que sorrateiramente embutido nas tarefas de docência e pesquisa.

Nesse sentido, a demanda por recursos financeiros é mais que urgente, seja nacionalmente, seja em nossas instituições e programas. Sua falta tem levado ao encerramento da atividade de vários periódicos, desde pequenos títulos até mesmo revistas academicamente consolidadas e do mais alto estrato no sistema de avaliação nacional. Uma posição hegemônica dentro da área de História e recorrente em grande parte das Humanidades é que os periódicos não devem realizar cobranças de taxas, seja dos autores (normalmente nomeadas como 'taxa de processamento de artigo', APC, article processing charge), seja dos leitores (taxas de assinaturas ou de acesso). Desse modo, e considerando que o vínculo da grande maioria das revistas é com as Instituições de Ensino Superior (IES) públicas, as alternativas são as chamadas públicas da modalidade programa editorial. Dentre os sistemas de financiamento, são poucos os que contemplam os novos periódicos e os que ainda não foram amplamente indexados; em geral, o foco tem sido os periódicos indexados nas grandes bases de dados nacionais e internacionais. As alternativas seriam as fundações de apoio e recursos das próprias IES, no entanto, têm sido cada vez mais raros esses editais. Ainda assim, raramente essas agências financiadoras contemplam este grupo. ${ }^{1} \mathrm{O}$ estrangulamento financeiro dos periódicos alija as comunidades de pesquisa no seu processo de crescimento e consolidação acadêmica, além de comprometer e reduzir a pluralidade de tópicos de pesquisa e, com isso, a bibliodiversidade do campo.

Diante do grave cenário nacional de descaso e flagrante desfinanciamento das pesquisas, que eleva esse quadro complexo a desafios presentes e futuros ainda mais

1 SITUAÇÃO DOS PERIÓDICOS CIENTÍFICOS brasileiros. Academia Brasileira de Ciências. 11 jun. 2021. Disponível em: http://www.abc.org.br/2021/06/11/manifestacao-situacao-dos-periodicos-cientificosbrasileiros/. Acesso em: 28 jun. 2020. 
exigentes, nossa atuação política é conclamada a uma dupla empreitada, que só podemos enfrentar na convergência de esforços. A primeira é lutar pelo reconhecimento e pelo financiamento, sempre! Mas é também fundamental lembrar o quanto pode ser crucial uma cultura de pesquisa e formação que valorize as revistas científicas da área, no âmbito do uso e dos trabalhos para sua produção.

\section{Assinam (até o dia 06/12/2021):}

- Aldrin Castellucci - Editor-chefe da Revista Mundos do Trabalho

- Alessander Kerber - Editor-chefe da Revista Anos 90

- Andréa Slemian - Editora da Revista Brasileira de História (ANPUH)

- Ângela Meirelles de Oliveira - Editora da Revista Tempos Históricos

- Artur Nogueira Santos e Costa - Editor da Revista Em Tempo de Histórias

- Breno Arsioli Moura, Ermelinda Moutinho Pataca, Indianara Lima Silva, Rômulo de Paula Andrade - Editores da Revista Brasileira de História da Ciência (RBHC)

- Camila Condilo - Editora-chefe da Revista Mundo Antigo em Resenha

- Carolina Amaral de Aguiar - Editora-chefe da Revista Antíteses (UEL)

- Cláudia Maria das Graças Chaves - Editora da Revista Almanack (UNIFESP)

- Claudia Rodrigues - Editora da Revista M. Estudos sobre a morte, os mortos e o morrer (UNIRIO)

- Eduardo Henrique Barbosa de Vasconcelos - Editor da Revista de História da UEG/ Quirinópolis (Goiás)

- Erinaldo Cavalcanti - Revista Escritas do Tempo (Unifesspa)

- Ester Liberato Pereira - Editora-chefe da Revista Caminhos da História

- Flávia Florentino Varella - Editora-chefe da revista História da Historiografia

- Frank Antonio Mezzomo - Editor da Revista NUPEM (Universidade Estadual do Paraná/Unespar)

- Gilberto da Silva Francisco, Glaydson José da Silva - Editor da Revista Heródoto (UNIFESP)

- Gustavo Junqueira Duarte Oliveira, Uiran Gebara da Silva - Editores da Revista Mare Nostrum (USP)

- João Maia, Thaís Blank, Bernardo Buarque de Holanda - Editores da Estudos Históricos (CPDOC/FGV)

- Josianne Francia Cerasoli - Editora da revista Urbana, Revista Manduarisawa

- Juniele Rabêlo de Almeida, Marina Annie Martine Berthet Ribeiro, Ynaê Lopes dos Santos - Editoras da Revista Tempo (UFF)

- Karina Anhezini - Editora-chefe da Revista História (São Paulo) (UNESP) 
- Luiz Antonio Dias - Editor científico da Revista Projeto História (PUCSP)

- Luiz César de Sá - Editor da Revista História, Histórias

- Marcelo Cheche Galves - Editor da Revista Outros Tempos (Universidade Estadual do Maranhão/UEMA)

- Marcos Cueto - Editor científico -, Roberta Cardoso Cerqueira - Editora executiva de História, Ciências, Saúde - Manguinhos (FIOCRUZ)

- Marcos Eduardo de Sousa - Assistente editorial no Fórum de Editores da ANPUH- Brasil

- Miriam Dolhnikoff - Editora da Revista de História (USP)

- Monica Martins da Silva - Editora da Revista História Hoje (ANPUH- Brasil)

- Odilon Caldeira Neto, Leandro Pereira Gonçalves - Editores da Revista Locus (UFJF)

- Ronald Lopes de Oliveira - Editor da Revista Dia-logos da Universidade Estadual do Rio de Janeiro (UERJ)

- Samira Peruchi Moretto - Editora da Fronteiras: Revista Catarinense de História (Universidade Federal da Fronteira Sul/UFFS e ANPUH-SC)

- Sandro Dutra e Silva - Editor da HALAC

- Silvia Liebel - Editora da Varia Historia (UFMG)

- Silvia Maria Fávero Arend, Maria Teresa Santos Cunha, Reinaldo Lindolfo Lohn Editores da Revista Tempo e Argumento (UDESC)

- Ulisses do Valle - Editor da Revista de Teoria da História (UFG)

- Valéria dos Santos Guimarães, Adrielli Souza Costa - Editoras da revista História e Cultura (UNESP) 